Cause of death identified by magnetic resonance imaging and autopsy in 53 cases

\begin{tabular}{|c|c|c|}
\hline Magnetic resonance and clinical history & No & Autopsy \\
\hline Cardiac ischaemia or cardiac death & 31 & - \\
\hline Pneumonia & 6 & - \\
\hline Aortic aneurysm & 3 & - \\
\hline Disseminated malignancy (one renal in origin) & 2 & - \\
\hline Cerebral infarction & 2 & - \\
\hline Cerebral haemorrhage & 1 & - \\
\hline Adult respiratory distress syndrome (after surgery) & 1 & - \\
\hline Pulmonary embolus (after surgery) & 1 & - \\
\hline Pulmonary oedema, pleural effusions, abnormal left ventricular wall signal & 1 & Ischaemic heart disease, pulmonary oedema \\
\hline Normal brain and lungs, left ventricular hypertrophy, pericardial fluid & 1 & Ischaemic heart disease \\
\hline $\begin{array}{l}\text { Old brain ischaemia, thorax and upper abdomen normal, history of } \\
\text { ischaemic heart disease }\end{array}$ & 1 & Ischaemic heart disease \\
\hline Fractured neck of femur, pulmonary consolidation, and oedema & 1 & $\begin{array}{l}\text { Ischaemic heart disease, pneumonia, gastric erosions, pseudomembranous } \\
\text { colitis fractured neck of femur }\end{array}$ \\
\hline Pulmonary oedema, empyema pericardial fluid, septicaemia & 1 & Pulmonary oedema, pneumonia, pericarditis, septicaemia, empyema \\
\hline Cardiomegaly, pulmonary oedema & 1 & Ischaemic heart disease \\
\hline
\end{tabular}

Knowing the clinical history is important for evaluating images, particularly when a specific clinical question has been raised. After the clinical history was discussed with the coroner, however, nearly half the cases referred by hospital doctors were accepted by the coroner without any postmortem examination.

Many cases from general practice were referred to the coroner because the doctor had not seen the patient for several weeks, even though the patient had a proved history of disease. The doctors were either too busy or unavailable to visit the mortuary to review the body after death. In cases such as these, where specific diseases could be evaluated, magnetic resonance imaging was most valuable.

Magnetic resonance imaging is a useful examination technique. The hard copy images are suited to audit and quality control, which are noticeably absent from the present system. Imaging is expensive, however, as we scan the head, thorax, and upper abdomen. The availability of scanners and radiologists' time also limit its use.
Contributors: $\mathrm{RB}$ wrote this paper with advice from all the authors. All four authors performed postmortem examinations. $\mathrm{RB}$ is guarantor.

Funding: No additional funding.

Competing interests: We performed the scans on private units, and we received private reporting fees (negligible compared to our usual private practice- that is, 53 cases over four years between four radiologists)

1 Brookes JAS, Hall-Craggs MA, Lees WR, Sama VR. Non-invasive peri-natal necropsy by magnetic resonance imaging. Lancet 1996;348:1139-41.

2 Cameron HM, McGrogan E. A prospective study of 1152 hospital autopsies: inaccuracies in death certification.J Pathol 1981;133:273-83.

3 Engel LW, Strauchen JA, Chiazze LR, Heid M. Accuracy of death certification in an autopsied population with specific attention to malignant neoplasms and vascular diseases. Am J Epidemiol 1980;111:99-112.

4 Carter RE, Jablon S, Mabuchi K. Agreement between death certificate and autopsy diagnoses among atom bomb survivors. Epidemiology 1994;5:48-56.

5 Corwin LE, Wolf PA, Kannel WB, McNamara PM. Accuracy of death certification of stroke: the Framingham study. Stroke 1982;13:818-21.

(Accepted 12 December 2001)

\title{
Rising incidence of Kawasaki disease in England: analysis of hospital admission data
}

Anthony Harnden, Bernadette Alves, Aziz Sheikh

Department of Primary Health Care, Institute of Health Sciences, University of Oxford, Oxford OX3 7LF

Anthony Harnden university lecturer

continued over

BMJ 2002;324:1424-5
Kawasaki disease is the leading cause of acquired heart disease in children in the developed world and may be a risk factor for adult ischaemic heart disease. ${ }^{1} \mathrm{~A}$ fifth of untreated children develop cardiac lesions during the acute phase of the disease. The cause remains uncertain. Epidemiological studies support an infectious agent inducing the disease in a genetically susceptible minority. Superantigen toxins have been implicated. Reported incidence rates differ considerably throughout the developed world with rates in Japan 10 times those in the United States and 30 times those in the United Kingdom and Australia. ${ }^{2-4}$ Hospital surveillance data suggest the incidence of Kawasaki disease in Japan has risen by over 50\% between 1987 and $1998 .^{2}$ To ascertain whether there had been a simi- lar rise in England, we investigated trends in hospital admissions for Kawasaki disease using routinely collected statistics from 1991 to 2000.

\section{Methods and results}

The hospital episode statistics database provides information on every inpatient admission to English NHS hospitals. Coding accuracy and reproducibility are better for acute conditions than for chronic disorders. ${ }^{5}$

We examined all emergency inpatient admissions for children younger than 17 years primarily diagnosed as having Kawasaki disease between 1 April 1991 and 31 March 2000. We excluded 293 interhospital transfers to avoid duplication. Coding of 


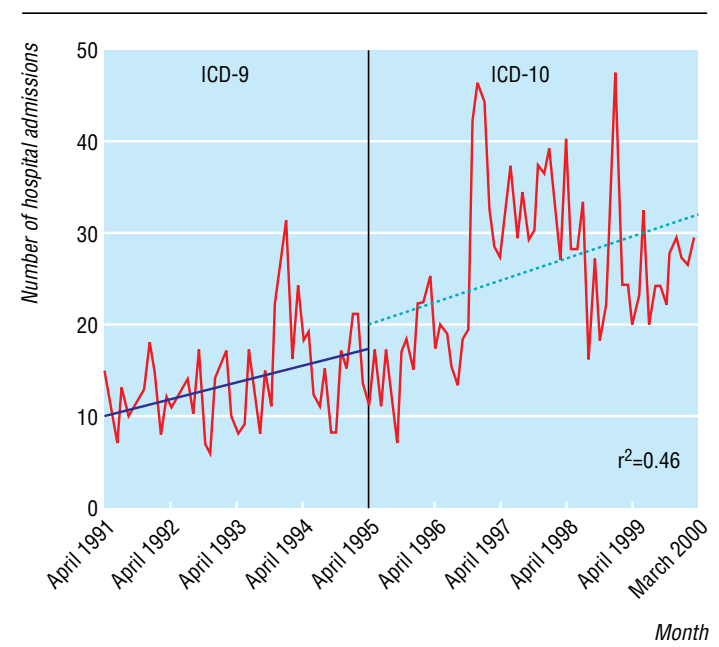

Monthly inpatient admissions for Kawasaki disease from April 1991 to March 2000 in England

diagnoses with ICD-10 (International Classification of Diseases, 10th revision) began in 1995. We analysed admissions coded with ICD-9 code 446.1 and ICD-10 code M30.3 separately and together. We derived overall admission rates specific to age from the 1999 estimates of the national midyear population. With monthly admissions as the dependent variable and the number of months from 1 January 1991 as the independent variable, we used linear regression to look at time trends over the study period.

During the nine years there were 2215 emergency admissions in children with a primary diagnosis of Kawasaki disease, 666 in the four year ICD-9 coded period and 1549 in the five year ICD-10 period. Median age at admission was 2 (interquartile range $1-4)$ years. Almost two thirds (61\%) of children admitted were boys; this proportion was consistent in all ages and across the study period. Annual admissions increased from 143 in 1991-2 to 308 in 1999-2000.

The incidence per 100000 children younger than 5 years doubled from 4.0 per 100000 (95\% confidence interval 3.4 to 4.8 ) in $1991-2$ to 8.1 per 100000 (7.1 to
9.2) in 1999-2000. The linear model (figure) provided evidence of a significant increase in monthly admissions: 0.15 (0.05 to $0.25 ; \mathrm{P}<0.001)$ extra admissions per month during ICD-9, 0.20 (0.07 to $0.32 ; \mathrm{P}<0.001)$ during ICD-10, and 0.21 (0.17 to 0.25 , $\mathrm{P}<0.001)$ in the two periods combined.

\section{Comment}

Hospital admissions for Kawasaki disease increased in England between 1991 and 2000. It is possible that this reflects an increase in recognition rather than incidence. After the demonstration in 1991 that in the United Kingdom only 7\% of children with Kawasaki disease received optimum immunoglobulin treatment, awareness of the importance of early diagnosis has been heightened. ${ }^{3}$

The incidence of Kawasaki disease among English children may have truly risen as it has in Japan. Explanations include a change in the infecting agent or a shift in susceptibility among young children. We recommend improved surveillance of Kawasaki disease to record further rises in incidence, to examine seasonal and geographical variations, and to report any changes in the pattern of clinical severity or the rate of complications.

We thank Tim Lancaster and David Mant for comments on earlier drafts of this paper and Adrian Cook for help with the data analysis.

Contributors: AH and AS had the idea for this paper. All three authors devised the study. BA analysed the data. $\mathrm{AH}$ drafted the paper and BA and AS commented on the text. AH is guarantor.

Funding: AS is supported by a NHS research and development national primary care training fellowship.

Conflict of interests: None declared.

1 Curtis N. Kawasaki disease. BMJ 1997;315:322-3.

2 Yanagawa H, Nakamura Y, Yashiro M, Oki I, Hirata S, Zhang T, et al. Incidence survey of Kawasaki disease in 1997 and 1998 in Japan. Pediatrics 2001;107:E33.

3 Dhillon R, Newton L, Rudd PT, Hall SM. Management of Kawasaki disease in the British Isles. Arch Dis Child 1993;69:631-8.

4 Royle JA, Williams K, Elliott E, Sholler G, Nolan T, Allen R, et al. Kawasaki disease in Australia, 1993-95. Arch Dis Child 1998;78:33-9.

5 Dixon J, Sanderson C, Elliott P, Walls P, Jones J, Petticrew M. Assessment of the reproducibility of clinical coding in routinely collected hospital activity data: a study of two hospitals. J Public Health Med 1998;20:63-6.

(Accepted 6 December 2001)
Department of Primary Health Care, Imperial College of Science, Technology and Medicine, London W2 1PG

Bernadette Alves health services researcher

Aziz Sheikh

NHS research and development national primary care training fellow

Correspondence to: A Harnden anthony.harnden@ dphpc.ox.ac.uk

\section{A memorable patient Useless again}

The next patient on the post-take ward round was a "straightforward" overdose. The senior house officer reported that the 21 year old girl was now well but had been having to look after her 91 year old grandmother. The ward sister confirmed that the girl was the "principal carer."

She looked, despite her age, like a child. She was obese, had pale, child-like skin with a flushed red face, and she was clutching a soft toy. Yes, she wanted to die. Then, quite spontaneously, she volunteered that her dad had died young of mesothelioma and that I had looked after him. Her manner implied unspoken gratitude for care given to a loving parent. She told me that she now lived away from home because she and her mum had blazing rows. Her general practitioner had wanted to help and had sent her to a psychiatrist. Unfortunately, the senior house officer who saw her made her feel even more useless than before.

We arranged for her to see our psychiatric liaison nurse. Then, as we left, she reached across and held out her hand to shake mine. As we walked back down the ward, I asked the ward sister if the mother had been in touch. Yes, she had been and had asked what the problem was. When she heard it was an overdose, the mother had commented, "There she goes. Once again, she has let her grandmother down."

Desmond Murphy consultant physician, St Mary's Hospital, Newport

We welcome articles of up to 600 words on topics such as A memorable patient, A paper that changed my practice, My most unfortunate mistake, or any other piece conveying instruction, pathos, or humour. If possible the article should be supplied on a disk. Permission is needed from the patient or a relative if an identifiable patient is referred to. We also welcome contributions for "Endpieces," consisting of quotations of up to 80 words (but most are considerably shorter) from any source, ancient or modern, which have appealed to the reader. 